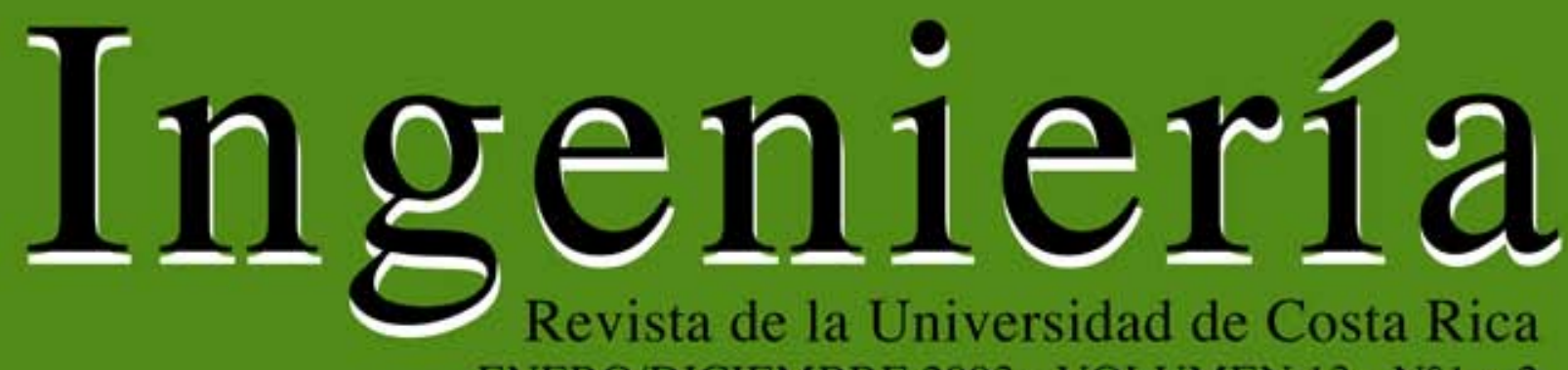
ENERO/DICIEMBRE 2003 - VOLUMEN 13 - N¹ y 2

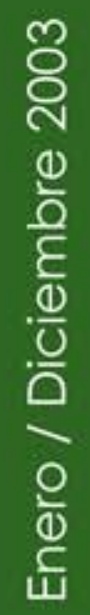

$\frac{m}{5}$
$\frac{c}{d}$
$\frac{5}{5}$
$\frac{\partial}{\circ}$

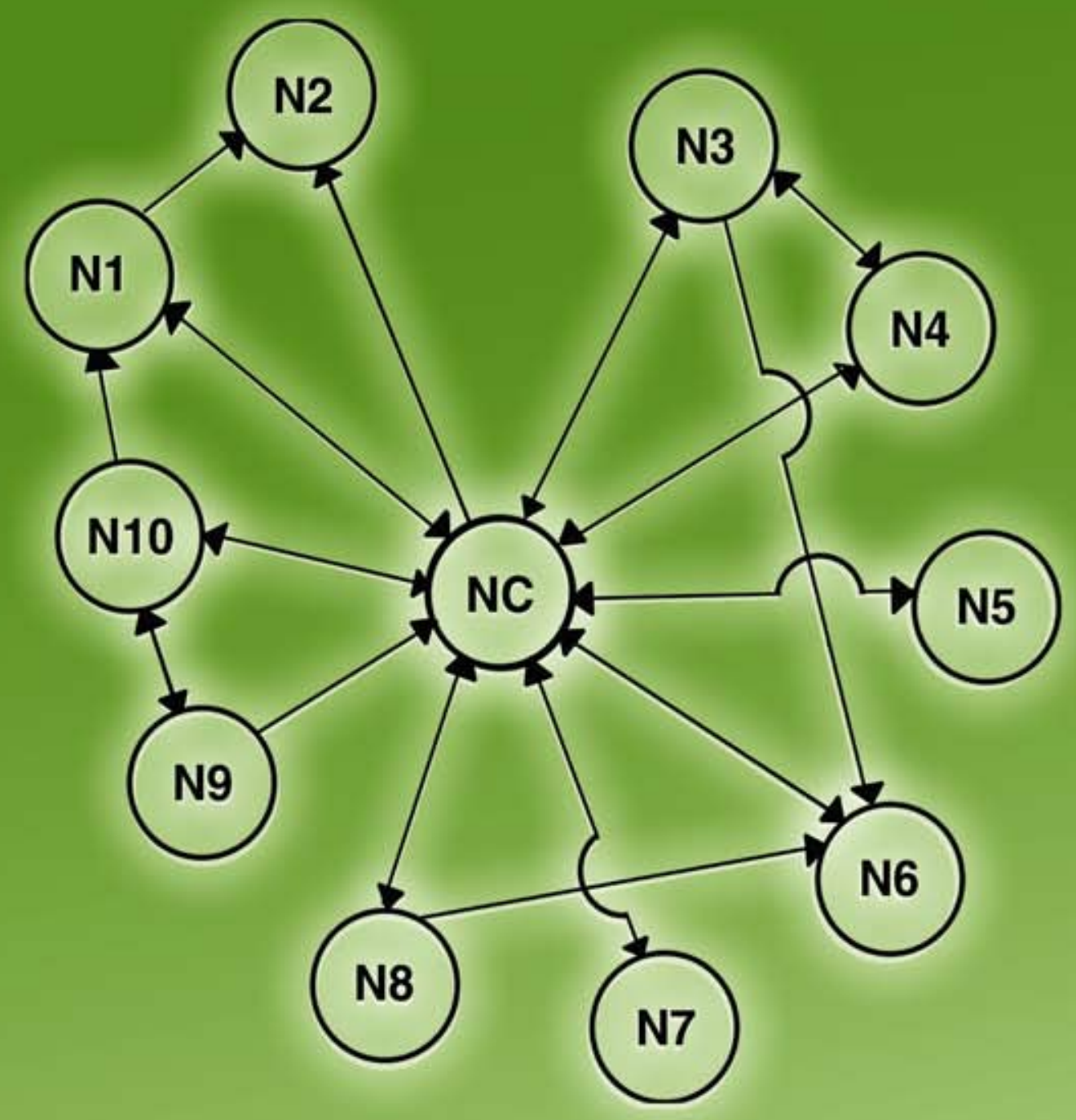

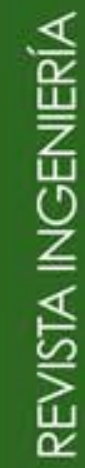




\title{
UN MODELO DE SIMULACIÓN DEL TRÁFICO DE UNA RED DE TRANSMISIÓN DE DATOS
}

Susan Chen Mok

\begin{abstract}
Resumen
El presente artículo muestra el proceso de creación de un modelo de tráfico de una red de transmisión de datos específica, mediante el software de simulación de redes COMNET III. El trabajo describe con detalle un ejemplo de este proceso. La temática, a veces difícil de conseguir en la literatura, es importante para los diseñadores de redes, que requieran ampliar sus conocimientos en el comportamiento, características, topologías y equipos de comunicación, necesarios para que el desempeño del tráfico de una red no se deteriore.
\end{abstract}

Palabras clave: simulación, redes LAN, tráfico de datos, COMNET III.

\begin{abstract}
This article describes how to create a traffic model of a specific data transmission network, using the network simulation software COMNET III. It shows in detail an example of the traffic modeling process, which is difficult to find in available research studies. This work is especially important to network designers, who need to know about network traffic behavior and have to decide on their characteristics, topologies and communication equipment, among others, in order to prevent a decrease in performance.
\end{abstract}

Keywords: Simulation, local area network, data traffic, COMNET III.

\section{INTRODUCCIÓN}

Para el presente trabajo se utilizó una red de área local, compuesta por computadores servidores y más de treinta microcomputadoras personales. El cableado de esta red local es UTP categoría 5.

Se utilizó el programa "Landecoder" para capturar el tráfico de la red, detalles de este programa pueden encontrarse en (Triticom, 1997).

Utilizando este software se extrajeron los datos del tráfico de la red, los datos incluyen:

- Información de cada paquete: longitud, tiempo de llegada, tiempo transcurrido desde el último arribo.

- Información de los protocolos de los diferentes niveles.

- Porcentaje de utilización de la red.
Las aplicaciones que usa la red incluyen: transmisión de archivos a las impresoras, transferencias de archivos a los sistemas de almacenamiento local, programas especializados, correo electrónico y transferencia de archivos dentro de la red y hacia fuera de ésta

\section{EL SISTEMA A MODELAR}

En las próximas secciones se identifican los elementos que se requieren para modelar el sistema de tráfico de la red estudiada.

\subsection{Identificación de componentes, atributos y actividades del sistema modelar.}

Todos los sistemas pueden ser descritos por:

1. Componentes: entidades independientemente identificadas de un sistema, cuyo desempeño colectivo determina la salida del sistema. 
2. Variables: aquellos atributos del sistema que toman diferentes valores bajo diferentes condiciones o distintos estados del sistema. Se pueden clasificar en variables internas y externas.

-Variables internas: aquellas cuyos valores están determinados por el desempeño de los componentes del sistema y describen el estado o condición del sistema en cualquier punto en el tiempo; también se llaman variables de estado.

-Variables externas: aquellas cuyos valores están determinados por el experimentador o influencias exteriores del sistema.

En el sistema estudiado se identifican las siguientes entidades, atributos y actividades del mismo:

\section{ENTIDADES}

- Estaciones

- Servidores

- Enrutadores, (routers)

- Conmutadores (switches)

- Enlaces entre los nodos.

- Fuentes de tráfico.

\section{ATRIBUTOS}

Tipo, capacidad de

buffer de los puertos.

Tipo, capacidad de

buffer de los puertos.

Tipo, capacidad de buffers, tiempo del procesamiento del paquete, tiempo del procesamiento del puerto, protocolo de enrutamiento.

Tipo, capacidad, tiempo del procesamiento del paquete, tiempo del procesamiento del puerto.

Tipo, velocidad de transmisión, protocolo de acceso.

Longitud de paquetes, tiempo entre arribos, número de arribos por unidad de tiempo.
Este conjunto de entidades se pueden clasificar de la siguiente forma:

1. Nodos: estaciones de trabajo, servidores, enrutadores, conmutadores, concentradores.

2. Fuentes de tráfico.

3. Enlaces.

Las actividades de un sistema son aquellas relaciones entre componentes y variables que controlan los cambios de estado en el sistema. Se pueden identificar las siguientes actividades:

- Arribo de mensaje a la red.

- Transmisión del mensaje a través de la red.

- Salida del mensaje de la red.

El sistema de red estudiado se puede modelar como un sistema de cola, como se muestra en la Figura 1.

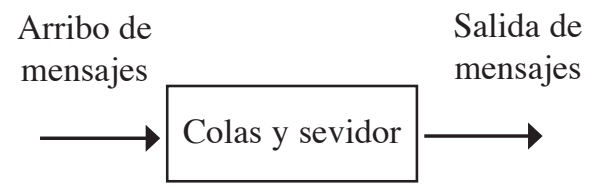

Figura 1. Modelo del sistema.

Las colas corresponden a las que se forman en los buffers de salida de los nodos hacia el enlace o canal. El servidor corresponde al canal que da el servicio de transmisión de los mensajes. Los mensajes arriban al buffer de salida de la estación para ser transmitidos a través del canal, y se reciben en el buffer de entrada de la estación destino.

La red estudiada es de tipo Ethernet y su método de acceso al medio es el CSMA/CD; este protocolo no permite más de un paquete en el canal. Un paquete llega al buffer de salida hacia el canal de la estación. La estación censa constantemente el canal, en el momento que no detecte señal de portadora, el paquete es puesto en el canal. La colisión ocurre porque al mismo tiempo varias estaciones, que tienen paquetes para transmitir, detectan que el canal está desocupado, y por lo tanto colocan simultáneamente su paquete en el canal. 
La disciplina de servicio de cola dicta que el primero en detectar que el canal está desocupado, coloque su paquete en el canal; es decir, el primer paquete que llega es el primero en transmitirse, con la variante de que se permite que lleguen al mismo tiempo varios paquetes, lo que provocaría una colisión en la transmisión que el mismo protocolo resuelve.

Para un análisis de rendimiento de un sistema se requiere la siguiente información:

1. Tiempo medio entre arribos de paquetes: atributo que se define para las fuentes de tráfico.

2. Tiempo medio de servicio: en el modelo propuesto el tiempo de servicio corresponde al tiempo de respuesta, pues el servidor es el canal; se denota como X.

3. Tiempo medio de espera: es el tiempo medio de espera del paquete en la cola, corresponde al tiempo que el paquete permanece en el buffer (memoria de contención) de salida del nodo antes de que sea transmitido por el canal; se denota como W.

4. Número promedio de arribos por unidad de tiempo: si se denota como el número medio de arribos por unidad de tiempo, o intensidad de arribo; este valor corresponde al inverso del tiempo medio entre arribos.

5. Tiempo medio de ocupación del sistema: se define en términos de tiempo medio de espera y tiempo medio de servicio:

\section{Sea}

$\mathrm{T}=$ tiempo medio de ocupación del sistema

$\mathrm{W}=$ tiempo medio de espera

$\mathrm{X}=$ tiempo medio de servicio

\section{Entonces $\mathrm{T}=\mathrm{W}+\mathrm{X}$}

Puesto que el tiempo de espera es el tiempo que el paquete está en el buffer, esperando ser servido, y el tiempo de servicio es el tiempo que dura la transmisión del paquete a través del canal, causando que el canal esté ocupado durante el tiempo de transmisión, tenemos que $\mathrm{N}=\bullet T$ es el número promedio de mensajes en el sistema.

6. Tiempo de respuesta: es un cálculo importante para medir el desempeño de la red. Corresponde al tiempo total que se requiere para enviar un mensaje desde el origen al destino, incluyendo los retrasos de transmisión y propagación, retrasos de procesamiento de paquetes en los puertos y el tiempo de espera en los buffers. Como se define el canal como el servidor, este tiempo es el tiempo de servicio.

7. Throughput: se relaciona con otra medida llamada "utilización" o "eficiencia del canal", se define básicamente, como la fracción de tiempo promedio en que un canal está ocupado y lleva paquetes buenos de información. De esta manera, sin considerar la sobrecarga u overhead (sobrecago o recargo), si el canal sólo lleva paquetes buenos cuando está ocupado, se puede señalar que throughput (rendimiento total) y "utilización" corresponden a lo mismo.

\subsection{Identificación de los parámetros del sistema a moldear.}

Los parámetros son aquellos atributos del sistema que no cambian durante la simulación (excepto con la orden del experimentador); suelen ser las variables de entrada.

En el sistema estudiado podemos identificar los siguientes parámetros:

Tipo de enlace

Velocidad de transmisión

Protocolo de acceso

Protocolo de enrutamiento

Tiempo promedio entre arribos

Capacidad de buffers 
Tipo de nodo

Velocidad de procesamiento del nodo

Longitud promedio de paquetes

Estos parámetros corresponden a las variables que el experimentador puede cambiar para evaluar diferentes alternativas de diseño, capacidades de la red, etc.

El resto de las variables señaladas corresponden a variables internas, se calculan dentro del sistema $\mathrm{y}$ el experimentador no las puede modificar, son:

- Throughput

- Tiempo de respuesta

- Retrasos

- Tiempo medio de espera

- Tiempo medio de servicio

- Tiempo medio de ocupación del sistema

- Intensidad de arribo

\subsection{Aplicaciones, características de los componentes y carga de la red}

En la red estudiada se "corren" las siguientes aplicaciones:

- Servidor Linux: aplicaciones de Internet, correo electrónico, transferencia de archivos, administración de correo, el servidor de archivos. Características: $266 \mathrm{MHz}, 64 \mathrm{Mb}$ RAM, 2 discos duros de 4 Gb cada uno, procesador Pentium II.

- Servidor NT: servidor utilizado para hacer pruebas. Características: $266 \mathrm{MHz}, 64 \mathrm{Mb}$ RAM, 2 discos duros de $4 \mathrm{~Gb}$ cada uno, procesador Pentium II.

- Servidor Linux: "corren" aplicaciones en Linux y se usa para investigación. Características: $100 \mathrm{MHz}$, procesador 486, disco duro de $640 \mathrm{Mb}, 16 \mathrm{Mb}$ RAM.

- Servidor Linux: servidor de archivos para las estaciones del taller y estudiantes.

Características: $25 \mathrm{MHz}$, procesador 386, disco duro de $100 \mathrm{Mb}, 16 \mathrm{Mb}$ RAM.
- Estaciones: “corren" las siguientes aplicaciones: OFFICE, AUTOCAD, VISSIO, MAPLAP, VISUAL, PEGASSO MAIL, EXPLORER, PSPICE, WINDOW WORKSTATION.

Características: $233 \mathrm{MHz}, 32 \mathrm{Mb}$ RAM, 1 disco duro de 3,5 Gb, procesador Pentium MMX.

De acuerdo con las consultas realizadas a los encargados de las redes y algunas observaciones efectuadas en el lugar, donde se encuentra el sector de la red en análisis, se determinó que mayo, junio, octubre y noviembre son los meses de mayor afluencia, especialmente los días lunes, martes, jueves y viernes, aunque por limitaciones de tiempo y recurso humano, y para efecto de la captura de información real del tráfico de la red, se supuso que el comportamiento del tráfico de la red es similar para cualesquiera de estos días.

\subsection{Nivel de detalle del modelo}

Se delimitó el estudio solamente al análisis del tráfico de la red descrita debido a las limitaciones de recursos y tiempo. Además, el software para la captura del tráfico se instaló en una microcomputadora que sólo podía capturar el tráfico del sector donde se encontraba.

Se propuso obtener información sobre el desempeño de la red: tiempos medios de respuesta, utilización y retrasos. Asimismo, recoger los datos para realizar el análisis de tráfico correspondiente: tiempos medios de servicio, tiempo medio entre arribos y tiempo medio de ocupación del sistema.

Se modeló el tráfico de la red, pero no sus componentes, puesto que el software de captura de tráfico que se utilizó provee sólo información acerca del tráfico de la red y no acerca del desempeño o uso de los componentes de ésta.

Se crearon modelos para el tráfico que llega al canal, buffers de entrada y salida de las estaciones, servidores y canal. Además, se modeló 
la topología de la red, la cual incluye estaciones, servidores, conmutador, concentradores y conexiones.

Se trató de modelar el tráfico actual de la red. Interesa aquí evaluar el desempeño del canal con respecto al tráfico ofrecido, tiempo de servicio y de respuesta, retrasos de transmisión de paquetes, etc. Sin embargo, no interesa el desempeño de las estaciones o servidores, ni el tiempo de servicio de los servidores, ni la cola de clientes para cada servidor, etc.

\section{DESARROLLO DEL MODELO DE SIMULACIÓN}

El siguiente apartado está compuesto por dos secciones, en primer lugar, se detalla el diseño del modelo en COMNET III, y en segundo lugar, se explica el proceso de validación del modelo propuesto.

\subsection{Diseño del modelo en COMNET III}

Esta sección describe el modelo del sistema y su creación en Comnet III. Se establece la relación entre los objetos que COMNET III utiliza para la creación del modelo y los objetos correspondientes en el sistema real. Se resumen los tipos de fuentes de tráfico que permite COMNET III para efectos de conocer las posibilidades en la generación de tráfico. Se determinan las capacidades de COMNET III para la obtención de la información de desempeño requerida, y por último se describe el modelo del sistema.

\subsection{COMNET III y el modelo}

COMNET III permite construir el modelo en tres grandes pasos:

- Definición de los componentes de la red

- Definición de los enlaces

- Definición de las fuentes de tráfico
Los nodos de la red corresponden a los siguientes componentes: estaciones, servidores, enrutadores, conmutadores. Los enlaces son del tipo "Ethernet" 10 base T. Las fuentes de tráfico se definen según cada componente de la red que genere tráfico, los componentes son las estaciones y los servidores.

\subsection{Las fuentes de tráfico de COMNET III}

COMNET III permite crear varios tipos de fuente de tráfico:

- Fuente de aplicaciones

- Fuente de mensajes

- Fuente de respuesta

- Fuente de sesión

- Fuente de llamadas

Las fuentes de aplicaciones se crean para los componentes con el fin de modelar aplicaciones que "corran" en el componente, por ejemplo, modelar un "software" que "corra" en la estación, y modelar el acceso a una base de datos en un servidor de base de datos, etc. Una fuente de llamada, se usa para modelar una generación de tráfico de circuito conmutado.

Una fuente de mensaje, es un generador de mensajes que se usa para enviar mensajes de un origen a uno o más destinos. Es útil para modelar muchas formas de transporte de datos, incluyendo tráfico de transacciones generales, correo electrónico y transferencia de archivos.

Una fuente de respuesta es un generador de mensajes que se usa para enviar mensajes en respuesta a mensajes recibidos. Es útil para modelar respuestas a transacciones, respuesta de base de datos, respuesta a correo electrónico, etc.

Estos mensajes están separados de los paquetes "ACK" que son generados por el algoritmo de control de flujo del protocolo de transporte.

Una fuente de sesión genera sesiones; cada sesión genera una secuencia de mensajes. Las sesiones 
son útiles para modelar circuitos conmutados o permanentes o bien, para modelar un proceso de arribo de mensajes por ráfaga (bursty).

El modelo estudiado necesita fuentes de tráfico en las estaciones y servidores de la red. Estas son fuentes de mensajes. No se modelarán las aplicaciones finales que "corren" en cada estación y servidor.

\subsection{COMNET III y los parámetros y variables internas del modelo}

Todos los parámetros propuestos para el sistema pueden ser descritos en COMNET III.

Tipo de enlace: CSMA/CD 10 Base T. Velocidad de transmisión: $10 \mathrm{Mbps.}$

Protocolo de acceso: CSMA/CD.

Protocolo de enrutamiento: standard.

Tiempo promedio entre arribos: 0,029 $3 \mathrm{~s}$.

Distribución de la probabilidad para los tiempos entre arribos:

Gamma(1, 0,03)

Capacidad de buffers: para estaciones 4 Mbytes de RAM y para servidores 10 Mbytes de RAM.

Tipo de nodo: computadoras, servidores, conmutador, concentrador.

Velocidad de procesamiento del nodo:

velocidad del procesador (estaciones: 233

MHz, servidores: $266 \mathrm{MHz}$ )

Longitud promedio de paquete: 624 bytes.

Las variables internas:

- Throughput: como se definió anteriormente equivale a "utilización" cuando no hay overhead. COMNET III brinda información del porcentaje de utilización del canal.

- Tiempo de respuesta: COMNET III da información del retraso promedio del mensaje por pares de estación. Este retraso corresponde al tiempo desde que se crea el primer paquete del mensaje, en el nodo origen y el tiempo que el último paquete del mensaje es recibido por el nodo destino, promediados sobre todos los mensajes enviados durante la simulación.

- Retraso de transmisión: corresponde al tiempo de transmisión de un paquete a través del canal. COMNET III brinda información sobre el retraso promedio de transmisión, definido como el tiempo transcurrido desde que el paquete es entregado en la entrada del enlace hasta que el paquete llega al final del enlace. Incluye el tiempo de transmisión, resolución de contención y tiempo de propagación.

- Tiempo medio de espera: en COMNET III este tiempo se incluye en el tiempo de respuesta anteriormente descrito, COMNET no separa este tiempo del tiempo de respuesta.

- Tiempo medio de servicio: bajo el modelo del sistema propuesto, el tiempo medio de servicio corresponde al tiempo medio de respuesta. Por lo tanto, el tiempo de servicio es el tiempo que tarda el canal en transmitir un mensaje desde el origen hasta el destino. Otra forma de calcular este tiempo sería tomar la velocidad de transmisión de la línea y dividir entre la longitud promedio de los paquetes transmitidos. Sin embargo, este último método no toma en cuenta los retrasos de creación de paquetes, la espera en los buffers y la propagación. Se tomará, entonces, el primer método propuesto para establecer el cálculo del tiempo de servicio.

- $\quad$ Tiempo medio de ocupación del sistema T: COMNET III no provee esta información. Corresponde al tiempo medio durante el cual el sistema está ocupado, es decir, el canal y los buffers están ocupados.

- Número promedio de arribos por unidad de tiempo: corresponde a la intensidad de arribo por minuto o número promedio de paquetes por minuto. COMNET III no provee esta información pero puede ser calculada mediante los datos que arroja. 


\subsection{Detalles del modelo de simulación}

\section{Suposiciones}

Por limitaciones de recursos se capturó el tráfico de ocho horas. Debido a algunas observaciones de los encargados de la red, decidimos capturar el tráfico un día viernes, suponiendo que ese día es similar a cualquier otro día entre semana.

Los datos obtenidos del tráfico real proveen información acerca de paquetes, por esta razón, al modelo de simulación se le suministró información sobre paquetes y no sobre mensajes.

Otra suposición es que todas las estaciones generan una carga de tráfico similar y el total de la carga generada hacia el canal coincide con la carga real.

\section{Modelo de los buffers de los enlaces}

Se modela el buffer del enlace para cada componente conectado:

$\begin{array}{lrll}\begin{array}{l}\text { Componente } \\ \text { conectado }\end{array} & \begin{array}{c}\text { Tamaño máximo } \\ \text { del } \text { buffer }\end{array} & \text { Unidad } \\ & \text { Entrada } & \text { Salida } & \\ & & & \\ \text { Estación } & 4000000 & 4000000 & \text { byte } \\ \text { Servidor } & 10000000 & 10000000 & \text { byte }\end{array}$

Suponiendo un buffer del tamaño de $4 \mathrm{Mb}$ en las estaciones y de $10 \mathrm{Mb}$ en los servidores, cualquier mensaje que no pueda ser enviado, porque el canal esté ocupado, queda almacenado en primera instancia en el buffer de la tarjeta de red, si existe, y en segunda instancia, si éste está lleno o no existe, en el buffer de la estación.

Cuando un paquete llega al buffer del enlace o bien, cabe completamente en él o es inmediatamente descartado, sin afectar los paquetes que están ya en el buffer.

\section{Modelo del enlace}

Se modela el canal como un enlace CSMA/CD (Carrier Sense Multiple Access with Collision Detection) 10 Base T:

Medio de transmisión: par trenzado

Longitud de segmento máximo en metros: 100

Longitud máxima en metros: 500

Velocidad de transmisión en km/s: 177000

Retraso de propagación máxima en ms.:

0,00282485

Es el tiempo para propagar la señal a través del enlace.

Rango de datos en Mbps: 10

Ventana de colisión en ms: 0,002

Período de tiempo durante el cual el enlace es vulnerable a una colisión después de que un nodo inicia su transmisión.

Tiempo de jam (atasco) en ms: 0,0032

Después de que un nodo reconoce una colisión, envía una señal especial jam de invalidación en el cable, ésta se mantiene por cierto período para alertar a los otros nodos que ha ocurrido una colisión. Este período es llamado intervalo o tiempo de jam. Después de una colisión, el enlace no se desocupa hasta que el tiempo de jam haya expirado. El concepto de señal Jam puede ser encontrado en distintos trabajos (Caci, 1995), (Tanenbaum, 1991) y (Walrand, 1991).

Desperdicio entre paquetes en ms: 0,009 6

Tiempo entre un paquete y otro.

Límite de sesión en bytes: 1024

En enrutamiento orientado a conexión, este límite es el máximo número de sesiones que pueden ser enrutadas concurrentemente a través del enlace. 
Paquete mínimo en bytes: 72

Paquete máximo en bytes: 1526

Overhead de paquete en bytes: 30

Límite para reintentar en ms: 16

Tiempo máximo que espera una estación para intentar de nuevo la transmisión después de sufrir la colisión.

Retraso límite en ms: 1000

Máximo de retraso permitido.

Los valores de todas estas variables se pueden encontrar en el trabajo de (Caci, 1995).

Las Figuras 2 a. y 2 b. muestran gráficamente algunos de estos conceptos.

\section{Modelo de los componentes de la red}

Se supone que los componentes modelados son perfectos. Se ignoran los efectos de los componentes sobre el tráfico para evitar enlazar el análisis a una arquitectura particular de los componentes. Los componentes simplemente son generadores de tráfico, no se analizan los efectos de las velocidades de procesamiento de los componentes en los retrasos de los paquetes.

\section{Modelo del tráfico ofrecido}

En la búsqueda de las distribuciones de probabilidad de los parámetros del modelo, se obtuvo que los tiempos entre arribos es mejor ajustado por la Función de Distribución de Probabilidad Gamma con r=0,03, 1/=1. Se utilizó para este trabajo el programa estadístico Systat, detalles de este programa pueden ser encontrado en (Wilkinson, 1990).

Para modelar el tráfico ofrecido se utilizó esta función de distribución para generar los tiempos entre arribos. Tomando en cuenta que este tiempo entre arribo fue obtenido de los datos observados del tráfico real, se modeló una fuente de tráfico para cada uno de los nodos de procesamiento y computación, con tiempos entre arribo generados por la Función de Distribución Gamma con parámetros $\mathrm{r}=0,03,1 /=1$. El tiempo promedio entre arribos real de los paquetes que llegan al canal, provenientes de todas las estaciones fue de 0,029 $3 \mathrm{~s}$, la función Gamma con estos parámetros fue la que mejor modeló a los valores reales.

Los datos obtenidos del tráfico real proveen información acerca del paquete. Como no se tiene información sobre mensajes, se toma como unidad para la simulación el paquete, y sus longitudes promedios.

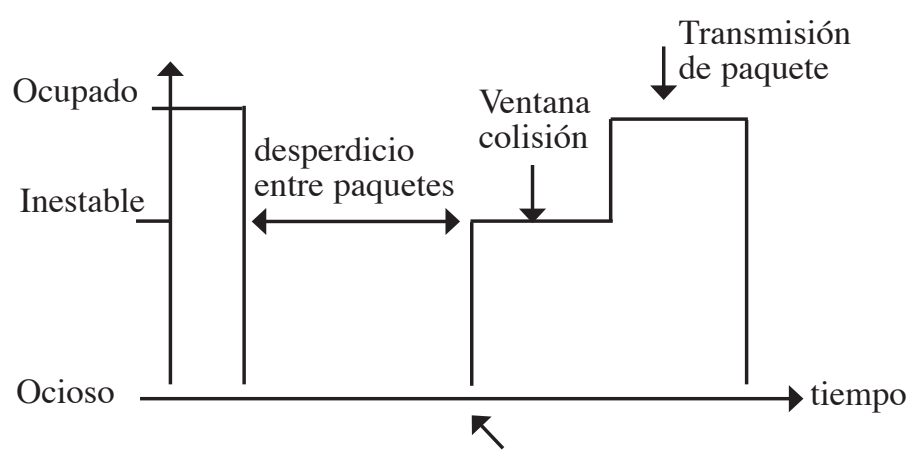

Nodo inicia la transmisión

Figura 2a. Transmisión exitosa. 


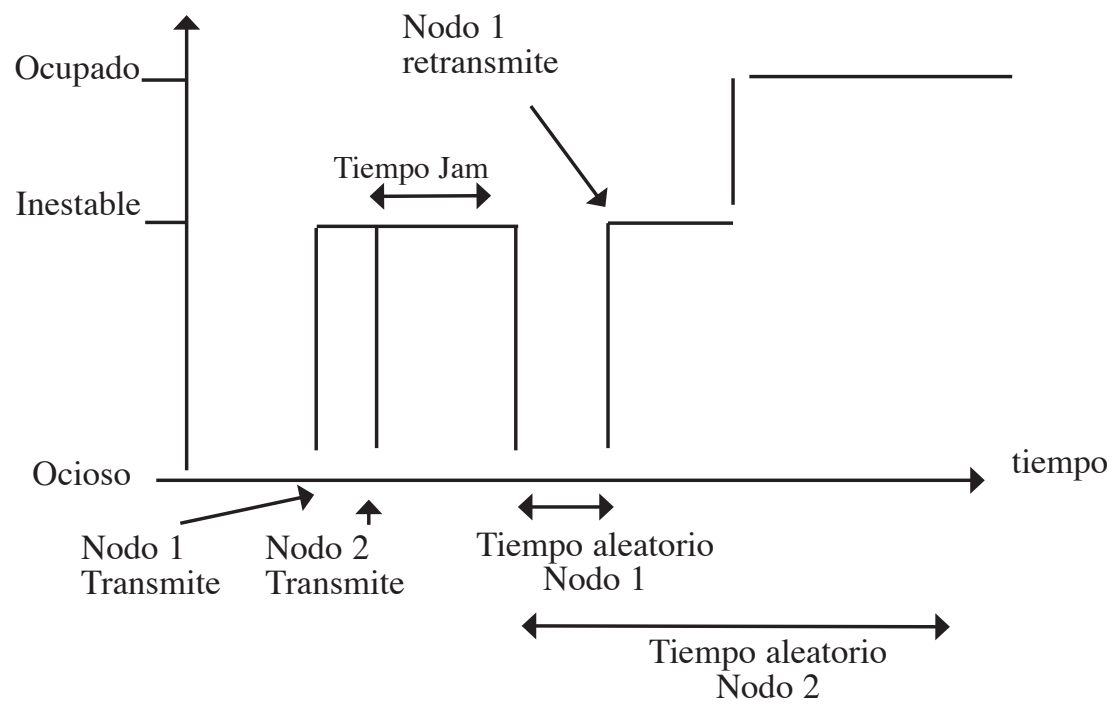

Figura 2b. Escenario de colisión.

A continuación se muestran los valores para los parámetros de las fuentes de tráfico:

Tiempoentre arribos: Distribución de Probabilidad Gamma(1, 0,03)

Tamaño de mensajes: 624 bytes

Clase de enrutamiento: estándar

Protocolo de transporte: TCP/IP Microsoft

El Cuadro 5 muestra las probabilidades definidas a cada destino para el envío de los mensajes desde cada fuente de mensaje.

A los servidores no se les definió ninguna fuente de mensaje, pues los servidores se modelaron como un nodo de procesamiento y respuesta a los cuales no se les define ninguna fuente de tráfico, sino que generan una respuesta, automáticamente, al recibir un mensaje de cualquier otro nodo.

Estos parámetros son simplemente para encaminar los mensajes a los diferentes destinos con la probabilidad definida. Estas probabilidades fueron definidas tomando en cuenta el tipo de estación y las aplicaciones que se corren en cada una de ellas, debido a que no se tenía información sobre la cantidad de tráfico generado por cada estación. Un estudio posterior puede orientarse a modelar específicamente cada componente de la red y el tráfico generado por cada uno de estos componentes.

\section{VERIFICACIÓN, CORRIDA Y VALIDACIÓN DEL MODELO}

La construcción o el desarrollo de un modelo de simulación requiere una evaluación que permita concluir si el modelo se ajusta al sistema real.

Para llevar a cabo esto, después de la creación y desarrollo del modelo, utilizando el COMNET III, se debe realizar la verificación, corrida y validación del modelo. Después de la verificación, se ejecutó las corridas de simulación y luego se procedió a la validación del modelo. En las próximas secciones se describen estos dos últimos procesos.

El proceso de verificación del modelo lo realiza el propio software de simulación COMNET III, 
Cuadro 5. Probabilidades de envío de mensajes Fuente de Mensaje

$\begin{array}{lccccc}\text { Lista destino } & \text { MsgProf } & \text { MsgProf2 } & \text { MsgAdm } & \text { MsgTall } & \text { MsgEst } \\ \text { MicrocAdm } & 0,05 & 0,02 & 0,2 & 0,2 & \\ \text { MicrocEst } & 0,05 & 0,05 & & & 0,2 \\ \text { Serv1 } & 0,5 & 0,7 & 0,5 & 0,7 & 0,64 \\ \text { MicrocProf1 } & 0,15 & 0,15 & 0,15 & 0,04 & 0,04 \\ \text { Serv2 } & 0,1 & & & & \\ \text { Serv3 } & 0,05 & 0,03 & & & 0,01 \\ \text { MicrocProf2 } & 0,05 & 0,05 & 0,05 & 0,01 & \\ \text { MicrocTall } & 0,05 & & 0,1 & 0,05 & \\ \text { Serv4 } & & & & & 0,11\end{array}$

por tal razón no se incluye la descripción de este proceso.

\subsection{Defínición de corrida}

Para la definición de la corrida de simulación se requiere establecer el tiempo de la corrida y el número de réplicas.

Se define el tiempo de corrida de simulación como el tiempo que se desea simular el modelo.

Por ejemplo, si se estudia el comportamiento de la red en un día normal de trabajo, el tiempo de corrida sería de 8 horas; si se estudia el comportamiento de los arribos en un minuto, el tiempo de corrida sería de 1 minuto.

Cabe aclarar que el tiempo de la simulación del modelo, no necesariamente coincide con el tiempo real; por ejemplo, un minuto de simulación no necesariamente coincide con un minuto real. Depende del modelo y el detalle deseado, así un minuto de simulación puede tardar mil segundos o varios minutos.

El número de réplicas deseadas, se refiere al número de veces que se requiere la repetición de la simulación, generando para cada réplica valores independientes para las variables definidas.
Una vez definidos ambos elementos, se inician las corridas de simulación para obtener los datos.

Para este trabajo se define corridas de simulación de una hora y otras corridas de cinco minutos. La ejecución de las corridas de simulación arrojó datos sobre las cantidades de arribos durante una hora y durante cinco minutos. Además, se definieron corridas de simulación con hasta cinco réplicas, para estudiar el comportamiento de las variables internas en cada una de las réplicas. Los datos utilizados para el análisis son un promedio de los datos de las diferentes corridas y de las diferentes réplicas para cada una de las variables analizadas.

\subsection{La validación}

La validación del modelo se basa en la comparación de las variables que el software "COMNET III" arroja con las equivalentes obtenidas de la captura del tráfico real.

Estas variables son:

- Porcentaje de utilización del enlace

- Promedio de la intensidad de los arribos

- Promedio de la longitud de los mensajes 
El proceso de validación se realizó en tres fases.

La primera fase de la validación se cumplió a través del análisis de las estadísticas obtenidas para el escenario diseñado.

La segunda fase incluyó el seguimiento de los eventos asociados que se generan desde que se recibe una solicitud de envío de un mensaje hasta que el mensaje llega a su destino.

La tercera fase en el proceso involucró la comparación de los resultados de la simulación con datos reales de desempeño disponibles obtenidos de la operación de la red. Esto incluyó los datos capturados del tráfico de la red en un día normal de trabajo.

\section{FASE 1}

Del promedio de la información de las cinco réplicas de las corridas de cinco minutos con los datos de las réplicas de las corridas de una hora se obtuvieron los siguientes resultados:

Total de paquetes enviados a través del enlace por minuto: 1498,94

Retraso promedio de transmisión del paquete: $0,8363 \mathrm{~ms}$.

Tamaño promedio del paquete: 624 bytes

Porcentaje de utilización: 1,672 $5 \%$

Retraso del paquete promedio:

De servidores a estaciones:

Serv1 a estaciones: 10,882 $5 \mathrm{~ms}$.

Serv2 a estaciones: $9,5187 \mathrm{~ms}$.

Serv3 a estaciones: $9,5944 \mathrm{~ms}$.

De estaciones a servidores:

Estaciones a Serv1: 7,179 $9 \mathrm{~ms}$. Estaciones a Serv2: 6,395 $3 \mathrm{~ms}$. Estaciones a Serv3: 5,994 $1 \mathrm{~ms}$.

De estaciones a estaciones: 5,240 $1 \mathrm{~ms}$.
Las variables internas propuestas con los valores calculados de la corrida de la simulación del modelo se muestran a continuación:

- Utilización por minuto (throughput): $1,6725 \%$

- Tiempo de respuesta: ver los datos anteriores sobre retraso del paquete promedio, puesto que el tiempo de respuesta sería lo mismo que el retraso de paquete en este modelo.

- Retraso promedio de transmisión de paquete: $0,83635 \mathrm{~ms}$.

- Tiempo medio de espera: está incluido dentro del retraso del mensaje.

- Tiempo medio de servicio: como se está tomando el canal como el servidor, esta variable es la misma que el tiempo de respuesta.

- Intensidad promedio de arribos: $=1498,94$ paquetes por minuto.

\section{FASE 2}

La solicitud de envío de un mensaje trae como consecuencia la generación de los siguientes eventos asociados:

- Creación de los paquetes del mensaje en la estación fuente.

- Colocación de cada paquete en el buffer de salida de la estación hacia el enlace.

- Transmisión de cada paquete por el enlace.

- Colocación de cada paquete en el buffer de entrada de la estación destino.

- Aceptación del paquete por parte del nodo destino.

- Envíode un “ACK”, señal de reconocimiento, por parte del nodo destino al nodo fuente. 
- Inicio del procesamiento del paquete en el nodo destino.

El tiempo transcurrido desde que se crea el primer paquete del mensaje en el nodo origen hasta que el último paquete del mensaje llega a su destino, se definió como tiempo de respuesta. En este tiempo se incluye: tiempo de creación del paquete, tiempo de espera en los buffers, y tiempo de transmisión y propagación. Esto es precisamente la definición del tiempo de respuesta o tiempo de servicio en el caso de que el servidor sea el canal.

Con base en estos datos, se hizo el seguimiento de los eventos asociados a la solicitud de envío de un mensaje hasta que éste llega a su destino.

\section{FASE 3}

De los datos obtenidos de la corrida de simulación se pueden establecer las siguientes comparaciones:

La intensidad de arribo es de 1499 mensajes por minuto, que es prácticamente igual a la intensidad de arribo promedio real de 1,500. Solo se presenta una diferencia del 0,66\%. De esto se puede decir que el modelo simula muy bien la intensidad de arribo real.

La longitud promedio del paquete dado para la simulación es el tamaño promedio de las longitudes de paquete real, 624 bytes.

La utilización del canal en la simulación fue del $1,66 \%$. Los datos reales del tráfico indicaban una utilización de alrededor del $0 \%$ al $2 \%$, exceptuando ciertos segundos en los que se registraron picos en la utilización.

El modelo es bastante exacto en cuanto a las variables analizadas, que son las únicas que se tomaron en cuenta debido a que las otras variables que arroja el software de simulación no tienen su correspondencia con las arrojadas por el software de captura de tráfico.

\section{CONCLUSIONES}

De acuerdo al trabajo realizado, se siguieron cinco grandes pasos para crear el modelo:

1- Estudio del sistema de red para obtener la información necesaria de los componentes de la red local así como del tráfico de la misma.

2- Determinación de los elementos necesarios que debían ser incluidos en el modelo de simulación.

3- Estudio de las características del software de simulación para conocer sus capacidades.

4- Diseño y desarrollo de los modelos de cada uno de los componentes de la red y de las fuentes de tráfico.

5- Verificación, realización de corridas de simulación y validación del modelo para garantizar que ésta se ajusta a la realidad.

Este trabajo pretende ser una guía para los diseñadores de red; asimismo, una orientación en el análisis del tráfico y desempeño de las redes de transmisión de datos con base en la metodología de simulación, con el fin de aportar mayores elementos e información para la toma de decisiones en lo que a la administración de redes se refiere.

Es importante aclarar que este estudio es sobretodo una guía didáctica para el análisis de tráfico de red. Los resultados obtenidos están muy relacionados con la topología de la red estudiada, las suposiciones hechas y las condiciones del mismo trabajo.

\section{BIBLIOGRAFÍA}

Bertsekas, D. \& Gallager, R. (1992). Data networks. (2a. Ed) USA.: Prentice-Hall Inc.

CACI. Comnet III major applications. Caci. Mayo 1999. http://www.caciasl.com/comnet_major_ apps_html. 
CACI. (1995). COMNET III User's manual -planning for network managers. Versión 1.1. USA: CACI.

CACI. (1998). A quick look at Comnet III. CACI. Setiembre. http://www.caciasl.com/ comnet/whitepapers/comnet.html

CACI. (1999).Comnet III Major Applications. CACI. Junio. http://www.caciasl.com/ comnet_major_apps_html.

Curry, T. (1997). Modeling a large financial network using Comnet III. CACI University Connection. Volume 1, Issue 1, Fall

Fowler, H. \& Leland, W. (1991). Local area network traffic characteristics, with implications for broadband network congestion management. IEEE Journal on Selected Areas in Communications. September, 7(9).

Frost, V. \& Melamed, B. (1994) Traffic modeling for telecommunicatios networks. IEEE Communication Magazine. March.

Gordon, G. (1978). System simulation. USA: Prentice Hall.

Grodzinsky, F. (1999) Networking and data communications laboratory manual. USA: Prentice Hall.

Gross, D. (1974). Fundamentals of queueing theory. USA. John Wiley \& Sons:

Gullon, A. (1988) Introducción a la Estadística Aplicada. Madrid. Alhambra.

Hammond, J. \& O’Reilly, P. (1988). Performance analysis of local computer networks. USA: Addison Wesley.

Hernández, R. \& Fernández, C.; Baptista, P. (1998). Metodología de la investigación. México, D.F.: McGraw Hill.
Hillier, F. \& Lieberman, G. (1997). Introducción a la investigación de operaciones. 4a.ed. México, D.F.: McGraw Hill.

Jain, R. (1991). The Art of computer systems performance analysis: techniques for experimental Design, Measurement, Simulation, and Modeling. USA: John Wiley \& Sons Inc.

Kleinrock, L.(1975). Queueing systems. Volume I: Theory. USA: John Wiley \& Sons Inc.

Kontogiannis, T. et al. (1999). Network simulation and an application in the study of telemetry data networks. Extraído de http://www. caciasl.com/comnet/whitepapers/telemetry/ telemetry.html.

Law, A. \& Kelton, D. (1982) Simulation modeling and analysis. USA: McGraw Hill.

Law, A. \& McComas, M. (1994). Simulation "software" for communications, networks: The state of the art. IEEE Communications Magazine. March.

Ludwig, J. \& Reynolds, J. (1988). Statistical ecology: A primer on methods and computing. USA: John Wiley \& Sons Inc.

Maisel, H, (1972). Simulation of discrete stochastic systems. Chicago: Science Research.

Marshall, W. T. \& Morgan, S.P. (1985). Statistics of mixed data traffic on a local area network. Computer Networks and ISDN Systems. 10, 185-194.

McHaney, R. (1991). Computer simulation, a practical perspective. USA: Academic Press.

Mendenhall, W. S. \& Richard L.; Wackerly, D. D. (1986). Mathematical statistics with applications. USA: PWS Publisers. 
Metcalfe, R. M. \& Boggs, D. R. (1976). Ethernet: Distributed packet switching for local computer networks. Communicacions ACM.

Miller, I. \& Freund, J. E. (1986). Probabilidad y estadística para ingenieros. 3 ed. México: Prentice Hall Hispanoamericana.

Miller, M. (1989). Troubleshooting ethernet. lan Technology.

Mood, A. \& Graybill, F. (1974). Boes, D. Introduction to the theory of statistics. $3 \mathrm{ed}$. McGraw Hill: USA.

Moskowitz, H. \& Wright, G. P. (1982). Investigación de operaciones. México: Prentice Hall Hispanoamericana.

Olabe, M.A. \& Ferro, A. Espinoza, K. (1998). Using COMNET III simulations to model video traffic and analyze multiplexing performance in an ATM network. Extraído de: http://www.caciasl.com/comnet/ whitepapers/video.html.

Pineda, E.B. de Alvarado, E.L.; de Canales, H. (1994). Metodología de la Investigación. Washington, D.C.: Organización Panamericana de la Salud.

Shoch, J. \& Hupp, J. (1980). Measured performance of an ethernet local network. Communications of the ACM. December, 12(23).

Stallings, W. 1991. A practical guide to queuing analysis. Byte. February
Tanenbaum, A. (1991). Redes de ordenadores. México: Prentice Hall Hispanoamericana.

Tanir, O. (1994). Defining requirements for a standard simulation environment. Computer. February.

Triticom.(1997). LANdecoder protocolanalyzers. USA: Triticom.

Yarden, S. (1998). Simulating electronic commerce on the internet using Comnet III. Extraído de: http://www.caciasl.com/ comnet/whitepapers/yarden.html.

Varhol, P. (1995). An Architecture for network simulation. Dr. Dobb's Journal. July .

Walrand, J. (1991). Communication networks: A firts course. USA: Richard D.Irwin Inc. and Aksen Associates Inc.

Wilkinson, L. (1990). Systat: The system for statistic. Evanston, II, Systat Inc.

Wilkinson, L. (1990). Sygraph: The system for graphics. Evanston, II, Systat Inc.

\section{SOBRE LA AUTORA}

\section{Sc. Susan Chen Mok}

Profesora de computación, Sede del Pacífico Universidad de Costa Rica.

Teléfono: (506) 661-1111,

Facsímil: (506) 661-2501

Correo electrónico: schen@cariari.ucr.ac.cr 